\title{
Preventing a covid-19 pandemic
}

\author{
We need to think beyond containment
}

\author{
John Watkins consultant epidemiologist
}

Public Health Wales, Cardiff, UK

In the aftermath of the 2009 H1N1 global threat, the Department of Health's pandemic preparedness planning team paid particular attention to the value, or otherwise, of containment as a strategy to prevent spread. In 2009 considerable time and effort were spent on a catch, isolate, and treat approach in the early stages of the emerging pandemic, and public health teams were expending considerable energy with, as it turned out, little effect. The resulting UK Influenza Pandemic Preparedness Strategy $2011^{1}$ emphasised the need to maintain the continuity of essential services and continue everyday activities as far as possible.

\section{Catch and isolate}

In a recent speech in the House of Commons, Matt Hancock, the UK secretary of state for health and social care, highlighted the mainstay of the government's approach, as set out in the plan: contain, delay, research, and mitigate. ${ }^{2}$ In relation to influenza, the plan sees these phases as detection, assessment, treatment, escalation, and recovery, and during the assessment phase it emphasises the need to actively find, test, isolate, and treat cases-our current approach to covid-19. Unlike for influenza, no vaccine or antiviral agents are available for covid-19, and the mainstay of treatment is supportive care, in high dependency units if necessary, for the most critically ill patients.

In 2003 the catch-and-isolate policy did curtail the outbreaks of severe acute respiratory syndrome (SARS), ${ }^{3}$ but will such an approach be successful with covid-19, which has already caused a nationwide epidemic in the most populous country in the world, with new fires starting on every continent? While this isolation and containment policy approach prevails, towns in Italy and whole countries, such as Iran, are being quarantined, with boundaries and borders closed at gunpoint. ${ }^{4}$ Under China's totalitarian regime, it has been possible to put in place draconian public health measures that in some cases seem to be an infringement of human dignity, but it is impossible to see how this could operate in the democratic states of the Western world.

\section{Plan for the worst}

Experience with SARS and the 2009 influenza pandemic showed that containment can buy us some time, ${ }^{1}$ and it has done so with covid-19. But containment in the face of a pandemic will go only so far, and we must use this time wisely. We need to start planning for an escalation in our response to new coronavirus infections and a surge in demand across the health and social care sector; the expectation must be that our unscheduled care services and the wider NHS, which are already stretched, will be severely challenged even by a modest increase in cases.

Bhatia and colleagues estimated that, although travel restrictions with China may have reduced transmissions, two thirds of all cases exported from China remain undetected. ${ }^{5}$ This assessment by the group at Imperial College London is now being played out, with community spread of the virus being seen in many countries, and the US Centers for Disease Control and Prevention (CDC) expressing the view that current global circumstances suggest it is likely this virus will cause a pandemic. ${ }^{6}$ We live in a world that is globally connected, in terms of the movement of people, goods, and food, while even within close knit communities, such as those currently locked down in Italy and elsewhere, the ideal conditions exist for the virus to spread from person to person. In one of the most cited research papers from the 1990s, Watts and Strogatz showed that the "small world" structure of society facilitates rapid disease propagation between distant and apparently unconnected communities, resulting in sporadic outbreaks that seem to start spontaneously, undermining even the most stringent attempts at containment. ${ }^{7}$

The clinical features of covid-19 are well documented, with most people displaying mild symptoms or none at all and deaths occurring mainly in elderly and chronically ill patients. This is not the public perception as played out in the media and reinforced by gunpoint quarantine.

Given the lessons from 2009-which taught us that containment for a globally disseminated disease was futile-and accepting that most of the exported covid-19 cases from China (and elsewhere) are undetected, is it not time to admit that a global pandemic is upon us? The World Health Organization is reluctant to say so. Once the disease is recognised as a global pandemic, nations, commerce, and healthcare can move into a much more rational phase with resources targeted at those most at need.

The healthcare system in the UK is, like that in many countries, at breaking point dealing with the routine demands placed on 
it. It is therefore vital that attention moves as quickly as possible to plan for this escalation in demand and identify how we reconfigure services to cope. We should plan on the assumption that most of the population may contract the virus with few or no long term effects, while harnessing vital secondary healthcare resources to treat the small percentage of people who become seriously ill.

Competing interests: I have read and understood BMJ policy on declaration of interests and declare that I was a member of the Department of Health's pandemic influenza preparedness team.

Provenance and peer review: Not commissioned; not externally peer reviewed.
1 DH Pandemic Influenza Preparedness Team. UK influenza pandemic preparedness strategy 2011. Department of Health, 2011.

Covid-19: Health Secretary's statement to Parliament. 26 February 2020. https://www. gov.uk/government/speeches/covid-19-health-secretarys-statement-to-parliament

3 World Health Organization. The world health report 2003-shaping the future. Chapter 5. SARS: lessons from a new disease. 2003. https://www.who.int/whr/2003/en/

4 Coronavirus: quarantine raises virus fears in northern Italy. BBC News 2020 Feb 25. https://www.bbc.co.uk/news/world-europe-51628084.

5 Bhatia S, Imai N, Cuomo-Dannenburg G, et al. Relative sensitivity of international surveillance. Imperial College London, MRC Centre for Global Infectious Disease Analysis. 2020. https://www.imperial.ac.uk/mrc-global-infectious-disease-analysis/news--wuhancoronavirus

6 US Centers for Disease Control and Prevention. Coronavirus disease2019(Covid-19): situation summary. https://www.cdc.gov/coronavirus/2019-nCoV/summary.htm/

7 Watts DJ, Strogatz SH. Collective dynamics of 'small-world' networks. Nature 1998;393:440-2. 10.1038/309189623998

Published by the BMJ Publishing Group Limited. For permission to use (where not already granted under a licence) please go to http://group.bmj.com/group/rights-licensing/ permissions 